\title{
UMA ABORDAGEM DE TÓPICOS DA MECÂNICA ROTACIONAL USANDO PROBLEMATIZAÇÃO MEDIADA POR ATIVIDADES DIDÁTICAS CONSTRUTIVISTAS
}

\author{
AN APPROACH TO TOPICS OF ROTATIONAL MECHANICS USING \\ PROBLEMATIZATION MEDIATED BY CONSTRUCTIVIST DIDACTIC ACTIVITIES
}

\author{
Cassiano Zolet Busatto ${ }^{1}$, Carlos Ariel Samudio Pérez ${ }^{2}$, Cleci Teresinha Werner da Rosa ${ }^{3}$ \\ Recebido: maio/2020 Aprovado: outubro/2020
}

\begin{abstract}
Resumo: Espera-se que o ensino de Física contribua com a formação dos estudantes, proporcionando-Ihes conhecimentos que lhes permita a interpretação de fatos, fenômenos naturais e processos tecnológicos. Entretanto, pesquisas tem mostrado que o seu ensino tem se caracterizado pelo uso de estratégias pedagógicas que privilegiam a memorização e reprodução dos conteúdos. No campo da mecânica rotacional, por exemplo, percebe-se que a abordagem didática utilizada pela maioria dos livros didáticos, pouco está relacionada com situações cotidianas. Diante desse contexto o presente trabalho descreve uma pesquisa desenvolvida com o intuito de avaliar como uma sequência didática fundamentada em pressupostos construtivistas e num ensino por problematização, auxiliada por recursos digitais e atividades experimentais, contribui para o estudo de conteúdos da mecânica rotacional. A proposta foi aplicada a uma turma de professores de Física em formação inicial. A pesquisa é de natureza qualitativa e participante e utilizou instrumentos de avaliação o diário de bordo e questionários pré e pós-teste. Esses materiais permitiram fazer reflexões que sugerem que: o uso das problematizações colabora na identificação dos conhecimentos prévios e na condução dos alunos para a tomada de consciência da necessidade de aquisição de um novo conhecimento; os recursos digitais e as atividades experimentais destacam-se no sentido de auxiliar na aproximação com situações cotidianas e na compreensão de conceitos abstratos.
\end{abstract}

Palavras-chave: Ensino de Física, mecânica rotacional, problematização.

Abstract: Physics teaching is expected to contribute to the training of students, providing them with knowledge that allows to interpret facts, natural phenomena and technological processes. However, research has shown that Physics teaching has been characterized by the use of pedagogical strategies that favor the memorization and reproduction of the contents. In the field of rotational mechanics, for example, it can be seen that the didactic approach used by most textbooks is little related to everyday situations. In this context, the present work describes a research developed with the intention of evaluating how a didactic sequence based on constructivist assumptions and teaching by problematization, aided by digital resources and experimental activities, contributes to the study of rotational mechanics contents. The proposal was applied to a group of students in initial teacher training in physics. The assessment instruments (logbook and questionnaires) allowed reflections that suggest that: the use of problematization collaborates in the identification of previous knowledge and in guiding students to become aware of the need to acquire new knowledge; digital resources and experimental activities stand out in the sense of helping to approach everyday situations and to understand abstract concepts.

Keywords: Physics teaching, rotational mechanics, problematization.

https://orcid.org/0000-0001-7942-4815 - Mestre em Ensino de Ciências e Matemática (UPF). Universidade de Passo Fundo, Passo Fundo, Rio Grande do Sul, Brasil. busattocassiano@gmail.com

2 (iD) https://orcid.org/0000-0002-1976-9886 - Doutor em Ciências - Física (UFRJ). Docente do PPGECM, Universidade de Passo Fundo (UPF), Passo Fundo, Rio Grande do Sul, Brasil.samudio@upf.br

3 (iD https://orcid.org/0000-0001-9933-8834 - Doutora em Educação Científica e Tecnológica (UFSC). Docente do PPGECM, Universidade de Passo Fundo (UPF), Passo Fundo, RS, Brasil.cwerner@upf.br 


\section{Introdução}

O ensino de Física tem se caracterizado por atividades pedagógicas que privilegiam o exercício da memorização e repetição. Isso inclui, por exemplo, a resolução de problemas por meio da aplicação de fórmulas num processo que normalmente envolve uma sequência de passos que pouco tem contribuído para o desenvolvimento do pensamento crítico ou mesmo da apropriação significativa dos conteúdos. Como consequência do uso desse tipo de estratégia, por parte dos docentes, os alunos criam a impressão de que a disciplina de Física é um conjunto de fórmulas sem significado, que tem como objetivo apenas a resolução de problemas em provas, e vestibulares.

Segundo Gomes e Castilho (2010), o ensino de Física no Ensino Médio (EM) pouco tem despertado a atenção dos estudantes, pois, muitas vezes, não há espaço em sala de aula para discussão de temas de interesse dos discentes, prevalecendo uma desvalorização dos conhecimentos que emergem fora da sala de aula, o que ocasiona um afastamento do contexto vivido e do que é estudado na escola. De fato, a abordagem de conteúdos instigantes da observação, reflexão, criticidade, criatividade, colaboração e do diálogo, pode ajudar a envolver os estudantes na construção do seu conhecimento, valorizando suas experiências e saberes anteriores, e torna-os ativos no processo de ensino aprendizagem de Física.

Rosa e Rosa (2005) enfatizam que, do ponto de vista das leis e diretrizes da educação nacional, os conteúdos mínimos que deverão compor cada disciplina integrante da educação básica, são de certa forma livres, não havendo uma listagem direta destes conteúdos. Embora tenhamos na atualidade uma referência de currículo mínimo no país, expresso pela Base Nacional Comum Curricular (BNCC), podemos dizer o expresso por Rosa e Rosa (2005) ainda se mostra pertinente, uma vez a BNCC apenas elenca grandes tópicos, deixando por conta de cada docente a seleção das especificidades e da forma de abordar esses conteúdos.

Em muitos casos as atividades pedagógicas do professor na sala de aula são fortemente influenciadas pelo uso das obras didáticas sugeridas pelo Programa Nacional do Livro Didático (PNLD). Nestes casos, o livro didático pode-se tornar um limitador do trabalho do professor, sempre que seja utilizado de forma isolada, como por exemplo, quando usado como único guia para a elaboração das aulas ou para a atividade de resolução de problemas. Por outro lado, o livro didático pode privilegiar a abordagem de certos conteúdos em detrimento de outros.

Pesquisas efetuadas por Barbosa (2016), Costa (2015) e Azevedo (2015) mostram que há tópicos da mecânica rotacional (MR) que se encontram ausentes, ou com pouca ênfase, nos livros didáticos de Física do ensino médio aprovados no PNLD 2015. Para Azevedo (2015) a ausência da contextualização desses conteúdos, assim como a falta de atividades experimentais, nos livros didáticos abre uma lacuna na formação do aluno, o que pode afetar o seu interesse pela ciência e, possivelmente, resultar no aparecimento de dificuldades no acompanhamento das disciplinas de Física no Ensino Superior.

A pesquisa de Silva (2012), envolvendo professores de Física do ensino médio, evidenciou, que um dos empecilhos para a falta de temas da MR em sala de aula pode estar ligado à baixa qualidade com que geralmente esses conteúdos são abordados nos livros didáticos e também à dificuldade que os próprios educadores tiveram para compreendê-lo durante sua formação. 
A pouca ênfase dada à DR nas aulas de Física no ensino médio vai na contramão do que é estabelecido nas diretrizes nacionais vinculadas à educação, como os Parâmetros Curriculares Nacionais do ensino médio (PCN+) (BRASIL, 2002) e a própria BNCC (BRASIL, 2018) que indicam a importância da presença desses conteúdos no planejamento dos professores da educação básica. A BNCC (BRASIL, 2018) do ensino médio, por exemplo, descreve a importância de desenvolver nos estudantes competência para que esses possam realizar a avaliação de potencialidades, limites e riscos do uso de diferentes materiais e/ou tecnologias para tomar decisões responsáveis e consistentes diante dos diversos desafios contemporâneos. Nessa perspectiva, o documento sugere mobilizar estudos sobre o princípio de conservação de energia e da quantidade de movimento.

As constatações de que conteúdos da MR se encontram ausentes, ou com pouca ênfase tanto nos livros didáticos quanto no planejamento dos professores de Física do EM, assim como, a da falta de materiais didáticos que oportunizem a utilização de uma abordagem envolvendo situações mais próximas do cotidiano e contextualizada desses conteúdos incentivaram o desenvolvimento da presente pesquisa. $O$ estudo parte do seguinte questionamento: como uma proposta didática fundamentada no ensino por problematização e apoiada em diferentes ferramentas didáticas, contribui para o estudo da MR?

O trabalho descreve a elaboração de uma proposta didática fundamentada na utilização de situações problematizadoras, atividades experimentais e recursos digitais, bem como os processos de sua aplicação e de avaliação.

A pesquisa se caracteriza como do tipo qualitativa e participante. Qualitativa pois busca verificar como determinado fenômeno se manifesta nas atividades humanas, considerando-se o quadro de referências dentro do qual os indivíduos atuam e dão significado ao mundo. $\mathrm{E}$ participante pois o próprio pesquisador assume o papel de professor. Sendo assim, os instrumentos utilizados para a coleta dos dados foram os registros do professor (diário de bordo) realizados após cada encontro e questionários pré e pós-teste, respondidos pelos participantes.

\section{Aporte teórico}

Nesta seção, e como aporte a elaboração da proposta didática e as discussões do estudo, buscamos tecer considerações relevantes para o processo de construção do conhecimento em Física, especialmente no que se refere ao uso de problematizações e de diferentes recursos didáticos como apoio à aprendizagem, particularmente as atividades experimentais.

\section{Problematizações iniciais no ensino de Física}

Do ponto de vista do construtivismo, é necessário promover um ambiente educativo com envolvimento dos educandos nas atividades pedagógicas, para que se tornem sujeitos ativos, reflexivos e arquitetos de sua própria aprendizagem, é importante oferecer situaçõesproblemas que os cativem e os façam sentir a necessidade de aquisição de conhecimento. Neste sentido, as problematizações iniciais, indicadas nesta proposta didática, estão alinhadas com as argumentações defendidas por Delizoicov (2001). 
Para o autor, problematizar é um processo mediante o qual o professor simultaneamente procura o conhecimento prévio dos alunos, promove a discussão em sala de aula, com a finalidade de identificar possíveis contradições e limitações dos conhecimentos que vão sendo explicitados pelos estudantes. A identificação de possíveis inconsistências internas aos conhecimentos emanadas das falas dos estudantes permite, na sequência, que o professor elabore e proponha novas problematizações, sempre tendo como referência implícita, o conhecimento que deverá desenvolver como busca de respostas.

Do exposto anteriormente, observa-se que, as problematizações devem ter o potencial de gerar no estudante a necessidade de apropriação de um conhecimento que ele não tem e que ainda não foi apresentado pelo professor. Por tanto, na proposta didática aqui descrita, sugere-se o uso de problematizações referentes a situações reais, do dia a dia, do cotidiano, que os alunos já tenham presenciado ou conheçam, que tenham afinidade com o tema em estudo e possibilitem introduzir os conhecimentos desejados.

Sendo que o objetivo das problematizações é fazer com que o aluno sinta a necessidade da aquisição de outros conhecimentos, é recomendado que durante o desenvolvimento desta etapa, sejam utilizados variados recursos didáticos (como figuras, vídeos, ..), com a finalidade de melhor aproximar o aluno da situação apresentada na problematização, assim como para estimular a atenção e participação dos estudante. Há que lembrar sempre que, procura-se relacionar uma situação em discussão como um problema que precisa ser enfrentado.

A utilização de problematizações iniciais antes de se começar os estudos de um determinado conteúdo, está correlacionada com o defendido na Aprendizagem Baseada em Problemas (ABP). A ABP é uma metodologia de ensino caracterizada pelo uso de problemas da vida real para estimular o desenvolvimento do pensamento crítico e competências dos estudantes (RIBEIRO, 2010). As problematizações iniciais e APB apresentam muitas semelhanças, uma delas é o viés construtivista, uma vez que, qualquer uma delas presa pelo desenvolvimento cognitivo e habilidades dos estudantes, assim como, guardam semelhanças com as teorias de Ausubel, Bruner, Dewey, Piaget, entre outros.

\section{Atividades experimentais no ensino de Física}

Para Pinho-Alves (2000) as atividades experimentais no ensino de Física representam papel fundamental no processo de ensino e aprendizagem, por tanto devem estar inseridas no discurso do professor facilitando a indução do fenômeno didático que objetiva o ensino de saberes. Borges (2002), considera as aulas de laboratório contextualizadoras e afirma que, descartar a possibilidade de que os laboratórios didáticos tenham um papel importante no ensino de Ciências significa destituir o conhecimento científico de seu contexto, reduzindo-o a um sistema abstrato de definições, leis e fórmulas.

Numa perspectiva construtivista, e preocupada com a realização de práticas experimentais que primem pela construção do conhecimento e não pela realização de um conjunto de procedimentos, Rosa (2011) sugere uma proposta de estruturação didáticometodológica das atividades experimentais no ensino de Física. A proposta consiste numa espécie de guia organizador de roteiro e é dividido em três etapas: pré-experimental, experimental e pós-experimental. Segundo a autora a proposta de estruturação se diferencia 
dos tradicionais, pois, busca envolver ao máximo a participação dos estudantes na atividade, proporcionado momento de reflexões sobre seus conhecimentos prévios e planejamento de suas ações.

Para Rosa (2011), as diferentes etapas podem ser entendidas da seguinte maneira. $\mathrm{Na}$ etapa pré-experimental, os educandos devem ser levados a refletir sobre como realizar o experimento e sobre o que irão fazer. É um momento de contextualização, de formulação de hipóteses, de propiciar que os estudantes exponham os seus conhecimentos prévios.

Na sequência, a etapa experimental, tem-se a execução das atividades experimentais, isto significa executar aquilo que foi planejado anteriormente, testar e observar as hipóteses levantadas. Na execução das atividades experimentais, os sujeitos devem estar ativos intelectualmente e engajados com a atividade, de modo que sejam capazes de construir seus conhecimentos, assim, a atividade experimental poderá ser demonstrativa.

A terceira e última etapa, pós-experimental, é caracterizada pelo fechamento da atividade, um momento no qual é preciso analisar e refletir sobre os resultados obtidos, por esse motivo, representa a conclusão do experimento.

$\mathrm{Na}$ continuidade, vamos descrever uma proposta didática que operacionaliza o apresentado nesta seção para, a partir dela, descrever e avaliar sua utilização no contexto da sala de aula.

\section{A proposta e sua aplicação}

A proposta aqui apresentada foi estruturada didaticamente com base nos pressupostos do construtivismo, mais especificamente nas ideias de Laburú e Carvalho (2001) que defendem o pluralismo didático nas atividades pedagógicas. Também foram levadas em consideração as ideias de Rosa (2011) para a elaboração do guia organizador de roteiro para aulas experimentais.

A elaboração da proposta didática levou em consideração a necessidade de estimular a aquisição efetiva do conhecimento, de promover o envolvimento dos estudantes durante o processo de ensino de Física, e da procura por tornar os estudantes agentes ativos, participativos e administradores da sua aprendizagem. Para isto, buscou-se aproximar o contexto diário dos estudantes dos novos conteúdos abordados procurando, sempre, utilizar atividades diversas que valorizem e estimulem o diálogo. A proposta também buscou fornecer ao professor material para o planejamento de suas aulas. Entre os recursos disponibilizados estão: vídeos de atividades experimentais e simulações de livre acesso, encontrados na internet; hipertextos (textos com animações e imagens); sugestões para a realização de atividades experimentais; orientações para a construção de giroscópios e de um equipamento para estudo do momento de inércia e de torque, entre outros.

Por se tratar de uma proposta que contempla o uso de animações e vídeos, optou-se por disponibilizá-la numa plataforma virtual, site, que de agora em diante será denominado de site:dinarot. A construção do site:dinarot ocorreu na plataforma gratuita do Google Sites. Esta plataforma permite que o site seja acessado em diferentes dispositivos como, celulares, 
computadores e tablets. O site:dinarot encontra-se disponível no endereço https://sites.google.com/view/dinarot.

A proposta didática foi aplicada a um grupo de egressos do ensino médio, mais especificamente, acadêmicos no segundo semestre (2018) do curso de Licenciatura em Física de uma universidade localizada ao norte do Rio Grande do Sul. A turma que participou por livre adesão assinou o termo de consentimento livre esclarecido e esteve composta por 15 estudantes com faixa etária de 18 a 23 anos, destes, 11 sujeitos tiveram sua formação básica em escolas estaduais e 4 em escolas de rede particular. Pode-se afirmar que eles não tiveram envolvimento com os tópicos abordados na proposta didática - mecânica rotacional, em sua recente iniciada formação universitária, pois de acordo com o planejamento deste curso esses tópicos são abordados a partir do terceiro semestre.

A operacionalização da proposta foi disposta na forma de encontros, desenvolvidos por um dos autores deste artigo que doravante denominamos de "professor". Nos encontros foram abordados diferentes tópicos da mecânica rotacional, como apresentado na Tabela 1, tendo as seguintes etapas como estruturante dos encontros: problematizações iniciais; abordagem do conteúdo; e, atividades experimentais.

Tabela 1. Conteúdos abordados nos encontros.

\begin{tabular}{|c|c|l|}
\hline Encontro & Períodos & \multicolumn{1}{c|}{ Conteúdo e Atividades propostas } \\
\hline 1 & 2 & Velocidade Angular, Torque e Momento de Inércia. \\
\hline 2 & 2 & Caracterização do Momento Angular. \\
\hline 3 & 2 & Conservação do Momento Angular, exercícios e atividades experimentais. \\
\hline 4 & 3 & Variação do Momento Angular (precessão), atividade experimental. \\
\hline
\end{tabular}

A abordagem de cada tópico foi iniciada com o professor fazendo uma pergunta contextualizada usando recursos de mídia para apresentar imagens e/ou vídeos de situações reais, que sejam conhecidas pelos estudantes e estejam relacionadas com o tema em estudo. No primeiro encontro, por exemplo, ao tratar da velocidade angular, a pergunta efetuada foi referente ao comportamento das rodas de um trator comum de uso agrícola. Este tipo de trator tem por característica que as rodas dianteiras são menores que as rodas traseiras. A pergunta feita foi: Suponha que um trator esteja em movimento constante. A velocidade das rodas (dianteiras e traseiras) será igual ou diferente? Porque?

Para ilustrar a situação foi apresentada uma foto, retirada da internet, de um trator agrícola. Neste momento foram fomentadas as discussões entre aluno-aluno e aluno-professor com a intensão de evidenciar os conhecimentos prévios dos estudantes assim como as suas dúvidas e inquietações. O momento foi aproveitado pelo professor para delimitar o conteúdo em estudo e estimular a motivação pela aquisição do novo conhecimento. Neste sentido, o professor sempre teve o cuidado de levantar novas problematizações relacionadas a situações vivenciadas pelos estudantes no dia a dia ao invés de responder ou fornecer explicações sobre o assunto. 
Na sequência, foi iniciada a etapa da abordagem do conteúdo, para isto foi promovida a leitura, análise e discussão do material elaborado na forma de hipertexto (e disponível no site:dinarot) referente ao tópico em estudo, fazendo uso de vídeos e animações em GIF (Graphics Interchange Format) para complementar o discurso do professor. Todos os hipertextos utilizados na proposta foram desenvolvidos buscando introduzir as novas grandezas e os princípios físicos envolvidos nos movimentos rotacionais. Neste sentido, os recursos dos vídeos e das animações em GIF neles incluídos, permitiram controlar o ritmo da aula, aumentando ou diminuindo a rapidez da apresentação a critério do professor e de acordo com as atitudes mostradas pela turma. Permitiram também, agregar detalhes tais como representações vetoriais, por exemplo, que colaboraram nas explicações relativas ao comportamento de grandezas abstratas. Um exemplo disto pode ser observado na Figura 1, que corresponde a uma das fotos de uma animação em GIF. Está animação mostra um giroscópio fabricado por um dos autores desse artigo em movimento, e na Figura 1 são indicadas, em destaque, algumas das grandezas envolvidas no fenômeno em discussão. Ao falar dessas grandezas, está se referindo a um conjunto de vetores que estão contidos em um espaço tridimensional, o que se apresenta como um desafio para a devida abstração e identificação por parte de alguns estudantes.

Figura 1. Giroscópio em movimento. Em destaque algumas grandezas físicas envolvidas no fenômeno.

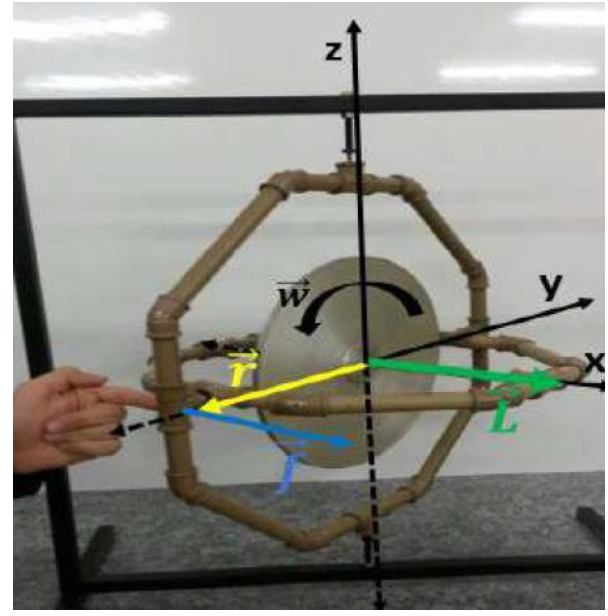

Fonte: os autores (2019)

Nos encontros também foram efetuadas atividades experimentais, que de acordo com a situação observada pelo professor na sala de aula, serviram para auxiliar na motivação e/ou entendimento de um determinado conteúdo, ou mesmo para finalizar um determinado estudo ilustrando uma situação prática que envolve os conhecimentos adquiridos.

No primeiro encontro, por exemplo, ao ser estudado o momento de inércia, as manifestações dos estudantes ante as problematizações iniciais evidenciaram para o professor que o conceito era "novo" para praticamente todos os integrantes do grupo. Para motivá-los, foi efetuada uma atividade experimental demonstrativa. Nessa atividade, um estudante deveria informar para os colegas, quando exercia maior força para iniciar a rotação de uma haste da qual estão penduradas duas massas, ora na extremidade, ora próxima ao centro de rotação, 
Figura 2. Após o momento de descontração e contextualização abordou-se a grandeza explorando sua definição conceitual e matemática utilizando hipertextos e animações em GIF.

Figura 2. Atividade experimental utilizada para motivar o estudo do momento de inercia

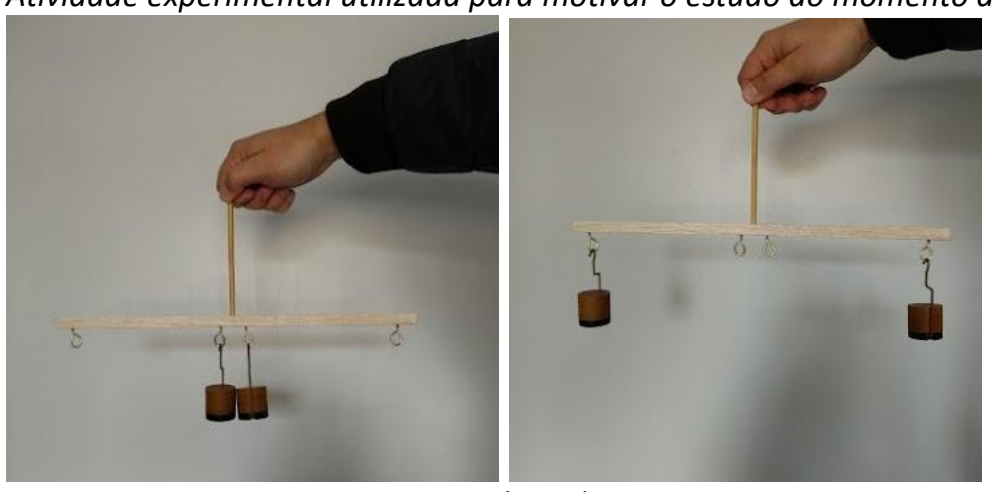

Fonte: os autores (2019)

Já no último encontro, foi efetuada uma atividade experimental como forma de "fechamento". A atividade estava relacionada ao estudo do funcionamento do giroscópio. Para isso, foram inicialmente retomados os conteúdos estudados nas aulas anteriores. A seguir, foi apresentado o aparelho. Todas os procedimentos metodológicos desenvolvidos e direcionados ao entendimento do funcionamento do giroscópio foram auxiliados pelo uso de hipertextos contendo vídeos e animações em GIF, que mostram suas aplicações tecnológicas, e ressaltaram a importância do uso deste aparelho na melhoria da qualidade de vida das pessoas.

Iniciou-se a explicação do equipamento com a apresentação de um vídeo. Nele havia uma simulação onde um corpo sofria a aplicação de torques externos e era possível identificar o vetor momento angular variando, na direção do torque. Após esse momento, foi proposto aos estudantes um desafio, onde eles deveriam identificar e qual seria o sentido de rotação do eixo do giroscópio quando for exercida uma força em algum de seus anéis, e também, realizado uma atividade experimental mediada por um roteiro guia construtivista seguindo o proposto por Rosa (2011).

Por fim, vale salientar que a utilização dos recursos da proposta é diversificado e se diferencia do estudo de algumas propostas já existentes. Como é o caso, por exemplo, do trabalho intitulado "Understanding the gyroscope sensor: a quick guide to teaching rotation movements using a smartphone", onde os autores utilizam o giroscópio do celular para explorar e coletar dados da velocidade angular (JESUS et al. 2018). O giroscópio dos celulares e o utilizado nesta proposta didática se diferenciam no princípio de funcionamento. O primeiro se baseia no Efeito Coriolis e o segundo na Conservação Momento Angular.

\section{A pesquisa}

A pesquisa desenvolvida foi de abordagem qualitativa, uma vez que busca compreender e analisar a realidade (Triviños, 1994), com o objetivo de verificar de que forma a organização da proposta didática contribui no processo de ensino-aprendizagem de conteúdos da mecânica rotacional, principalmente, quanto ao engajamento dos alunos frente as atividades desenvolvidas e o uso das diversas estratégias didáticas. A pesquisa também pode ser 
classificada do tipo participante (GIL, 2008), uma vez que o pesquisador assume a condução da sala de aula (professor) e é o observador.

Para a coleta dos dados foram utilizados dois tipos de instrumentos: o diário de bordo elaborado pelo professor sempre fazendo anotações no final de cada encontro e questionários pré-teste e pós-teste aplicados nos momentos anterior e posterior ao desenvolvimento da proposta.

Na perspectiva de Zabalza (2004), o diário de bordo constitui um espaço designado a registros, anotações e reflexões relacionadas a observações de momentos relevantes das atividades e as inferências dos alunos durante um processo pedagógico. Para Coppete (2014), o diário de bordo representa um instrumento pessoal e, por este motivo, pode apresentar sentimentos como frustrações, conquistas, dúvidas, impasses, inquietações e desabafos expressos em uma caminhada, os quais oralmente e presencialmente nunca fossem expressos.

A opção pelos questionários decorre da possibilidade de traçar comparações e fazer inferências sobre a efetividade da proposta em termos de apropriação de conceitos por parte dos estudantes. Neste sentido as questões que compõem ambos os testes são as mesmas.

\section{Análise dos dados}

\section{Diário de bordo}

Para análise dos dados coletados no diário de bordo foram estabelecidas categorias mediante aspectos relevantes a observar nos encontros. No entender de Bardin (2004), as categorias permitem discutir e refletir nos dados, de um processo educacional, sobre a relação entre aluno-aluno, aluno-professor e aluno-objeto, isto por sua vez permite destacar as características de uma determinada estratégia pedagógica. Como a intensão da pesquisa é avaliar as potencialidades e limitações da proposta didática, que podem ser atribuídas ao uso das ferramentas didáticas utilizadas, foram criadas três categorias a priori: problematizações, recursos digitais e atividades experimentais. A podemos verificar como o uso dessas ferramentas conseguem influenciar a motivação para aquisição do conhecimento, a participação, o convívio social e a postura dos alunos ao tratar dos conteúdos.

\section{Problematizações}

No que diz respeito ao uso das problematizações, na proposta didática, as anotações no diário de bordo permitem fazer algumas inferências. Num trecho dos registros feitos no primeiro encontro:

Ao iniciar as problematizações sobre velocidade angular, ficou evidente a heterogeneidade da turma, isto é, a segurança/confiança que alguns estudantes demonstravam ao responder, enquanto outros ficavam inquietos e seus olhares demonstravam estarem pensativos e decididos a entender ou compreender o que se estava questionando. Lembro de uma estudante sentada bem a frente que pedia ajuda ao colega ao lado, e o mesmo Ihe explicava sobre a diferença entre Velocidade Linear e Angular. 
Do trecho anterior, as problematizações referentes à velocidade angular parecem evidenciar uma postura comportamental dos estudantes que está alinhada com as ideias defendidas por Delizoicov (2001). A necessidade de aquisição de conhecimento ocorre quando o sujeito busca alternativas para compreender o que se está questionando, nesse caso, o auxílio do colega próximo. $O$ trecho mostra também a percepção do professor/pesquisador quanto às expressões faciais e comportamentais dos estudantes que, ao se depararem com a situaçãoproblema, apresentam curiosidade e interesse pelo conteúdo.

O modo como as problematizações são estruturadas é essencial. Nos questionamentos referentes ao conceito de torque foram utilizadas três situações-problemas, que se complementam aumentando gradativamente o grau de dificuldade (site:dinarot). O objetivo era o mesmo da situação anterior, gerar a necessidade de conhecimento e mapear os conhecimentos prévios, no entanto, ocorrem também instantes de tomada de consciência. No diário de bordo foi relatado esse momento:

Apresentei então a problematização referente ao Spinner, perguntando sobre o empurrão fornecido ao brinquedo para colocá-lo em rotação. Alguns estudantes logo falaram sobre o conceito de força, outros já familiarizados com a grandeza, utilizaram o termo torque ou momento de força. Apresentei então a segunda situação, que se referia a posição da força aplicada. Nessa, estava claro que a força em si, pode em alguns casos, não produzir rotação, $e$, por esse motivo, necessita de uma posição adequada. Ao apresentar o questionamento, o relacionado à aplicação de força em diferentes posições da roda, percebi sussurros: "É mesmo! Em alguns casos a força não produz rotação".

Os problemas estão relacionados às situações rotineiras vividas pelos estudantes, buscando ter uma significação, como sugerido por Delizoicov (2001), de modo a conscientizálos de que existe diferença entre os conceitos de torque e de força. Essa estratégia, de organizar uma série de perguntas deve ter o potencial de gerar no aluno a tomada de consciência, ou seja, de confrontar seu conhecimento com situações nas quais não se sustenta.

Por outro lado, as problematizações também podem ocasionar pouca participação dos estudantes quando o que se deseja ensinar está além do que eles já conhecem. Essa situação foi observada na abordagem do conceito de momento de inércia e do momento angular, ocasião na qual a turma demonstra pouca ou nenhuma participação. No entanto, isso não significa que não se devem apresentar problematizações, pelo contrário, o silêncio ou a pouca participação dos estudantes pode, provavelmente, estar relacionada a falta de conhecimentos prévios sobre o assunto tratado. $O$ trecho mostrado a seguir, descreve o momento da abordagem do conceito de momento de inércia. Ao realizar a abordagem, o professor assume a postura de fomentar nos estudantes a participação, procurando o momento adequado para introduzir o tópico e iniciar sua definição.

Iniciei a problematização sobre Momento de Inércia com a contextualização sobre a força aplicada a um tijolo e a um palete de tijolos. Ao apresentá-la, todos sem exceção, concordaram que para colocar o tijolo em movimento era necessário menos força. Logo em seguida apresentei a problematização sobre o arranjo experimental montado. Nesse momento, parte da turma ficou sem saber o que responder e outra concordava que quanto 
mais longe, mais força seria preciso para colocar o corpo em rotação. Questionei a turma se para as mesmas massas, em posições mais afastadas do eixo seria necessária mais força para colocar o equipamento em rotação, eles concordavam que quanto mais longe, mais força seria necessária, mas não utilizavam o conceito de Momento de Inércia em suas falas. Percebi que aquele conteúdo era novo para todos os integrantes da turma, e então apresentei o conceito, explicando que a posição da massa estaria relacionada com o mesmo.

No trecho apresentado, fica perceptível que a participação dos estudantes está relacionada com os conhecimentos prévios que eles possuem. O conceito de momento de inércia provavelmente não faz parte do planejamento curricular dos professores da educação básica, o que ocasiona uma lacuna na compreensão dos fenômenos relacionados aos movimentos rotacionais. À medida que o indivíduo conhece conceitos ou grandezas, o nível de participação aumenta, e, novamente, as características das problematizações aparecem, como o levantamento de hipóteses, a participação e a tomada de consciência. O trecho a seguir destaca o momento de abordagem do conceito de conservação do momento angular, onde há intensa participação dos estudantes.

Iniciei a aula com as problematizações do homem que coloca a roda do automóvel em rotação, e depois com a do rapaz que está sobre a plataforma giratória fechando e abrindo os braços. Na primeira problematização, era praticamente consensual que seria necessário a aplicação de uma força contrária, para pará-lo, então houve bastante participação e pouca diferença nas respostas. Na segunda situação, a participação se manteve, mas houve divergência nas respostas, cada aluno defendia seu ponto de vista. Após o rapaz ser colocado em movimento com os braços estendidos, sua velocidade era uma, e quando fechava seus braços começava a girar mais rapidamente. Questionei se o Momento Angular aumentava quando eles fechavam os braços. Um estudante estava convicto que sim, pois sua velocidade angular aumentava. Então disse a ele, para o Momento Angular aumentar deve haver torque aplicado, houve?

Neste trecho fica evidenciada a utilização dos novos conceitos por parte dos estudantes, o que permite a eles formularem suas novas perguntas ou hipóteses de maneira mais elaborada, assim como aumentar o nível de participação.

\section{Recursos Digitais}

O uso de tecnologias digitais oferece sensíveis mudanças na relação entre os envolvidos no processo de ensino e aprendizagem. Nesse contexto, vale analisar como esses recursos foram aceitos, e se contribuíram de alguma forma no desenvolvimento das aulas.

Passei então a abordar o conteúdo, explicando a primeira e a segunda problematização. Após a explicação utilizando os slides com equações e as animações, utilizei um trecho de um vídeo disponivel na Internet. O vídeo era relacionado a explicação da atividade experimental que foi realizada ao final da aula do Momento Angular. Nele os criadores acrescentam um elemento essencial, que é a representação vetorial das grandezas. No momento da apresentação do vídeo e da explicação, um aluno concordava com a cabeça aparentando ter entendido. 
Esta anotação do diário de bordo foi feita no segundo encontro e refere-se às atividades efetuadas na etapa de abordagem do conteúdo. O relato anterior mostra que o professor conclui a explicação utilizando um vídeo relacionado com a atividade experimental desenvolvida. O vídeo permite a inclusão de elementos que auxiliam no entendimento do comportamento das grandezas físicas envolvidas, grandezas essas que na própria a atividade experimental fica difícil incluir, e que a única maneira é abstraindo tal situação. Essa alternativa, embora não possua participação dos estudantes, parece ser bem aceita.

De acordo com Moran (1994), o material audiovisual facilita na compreensão daquilo que não temos presente fisicamente. Eles também possuem a vantagem de serem manipulados com recuos, avanços, repetições e pausas, a fim de se analisar e obter o maior número de informações possíveis. $\mathrm{O}$ apresentado pelos autores foi de encontro com o momento em que $\mathrm{o}$ vídeo é utilizado para contextualizar um determinado fenômeno:

Na etapa pré-experimental foi apresentado aos acadêmicos um vídeo. Nesse, um helicóptero de controle remoto era posto em funcionamento, ora com o estabilizador de cauda, ora sem o estabilizador de cauda. O vídeo foi reproduzido três vezes a pedido dos estudantes. Percebi que, a cada reprodução, eles atentavam-se a um novo detalhe.

Situações como a apresentada não são cotidianas, e demonstram estar distantes da realidade dos estudantes. Mas, os vídeos, como defendem os autores antes citados, possibilitam aproximar aquilo que está distante dos estudantes. Por outro lado, permitem o uso de recursos, que colaboram para a melhor observação e análise dos fenômenos, assim como, criam condições de maior participação e envolvimento durante a atividade.

\section{Atividades experimentais}

A atividade experimental é uma importante ferramenta de aprendizagem que pode ser manipulada pelo professor com o objetivo de ilustrar um fenômeno, ou pelos estudantes, para testar, coletar dados e manusear, em outras palavras, experimentar. A seguir uma anotação no diário de bordo.

Sobre o Torque, utilizei uma haste que continha 4 ganchos fixos. Um em cada extremidade e dois no meio. Pedi a participação de um aluno, e solicitei a ele que segurasse próximo a uma extremidade e que compartilhasse com os colegas sobre a força que ele fazia para manter a haste na horizontal, enquanto eu adicionava uma massa, ora na extremidade oposta, ora no meio. Ao realizar a atividade, o aluno mencionou: "Nossa! (risos) no meio fica bem mais leve". Deixei que o experimento transitasse pela sala, e observei que todos o manusearam.

O trecho relata o momento em que o professor utiliza um equipamento didático para contextualizar o conceito estudado; essa abordagem não utiliza nenhum roteiro, somente a interação com os estudantes. Como menciona Borges (2002), as atividades devem oferecer a oportunidade, seja ela de manusear ou observar, mas que permita conectar símbolos, e que possa se tornar um exercício de simbolização e representação. Nesse caso, entra a questão da sensação sentida pelo sujeito que aprende, na qual ele experimenta e compara a força que fez para manter a haste na horizontal modificando a posição da massa. 
As atividades experimentais também se mostraram eficazes ao serem inseridas antes de abordar um determinado conteúdo, com o objetivo de fomentar a motivação, a interação e o envolvimento dos estudantes na aula.

Eles ficaram em silêncio, e nada falaram. Questionei novamente. Ninguém ousou arriscar uma resposta. Peguei o rotor do giroscópio, e pedi a ajuda de um voluntário. Demonstrei a ele como eu queria que segurasse o brinquedo. Na sequência, com a ajuda de uma furadeira coloquei o rotor para girar. Entreguei o objeto, e disse a ele para mudar o eixo de posição várias vezes, compartilhando com os demais se considerava fácil ou difícil mudá-lo. O aluno não se conteve e começou a rir, dizendo "Eu não consigo! Empurro para um lado e ele vai para o outro"

Buscar aproximar os estudantes do que se deseja ensinar consiste em facilitar o processo de ensino e aprendizagem. É preciso considerar que nem todos os indivíduos que aprendem tiveram a oportunidade de presenciar, ver ou interagir com o que se deseja ensinar. Sem esse conhecimento prévio, faltam recursos para a interação e o diálogo. Neste sentido, o uso de um roteiro guia para a execução de atividades experimentais, pode estimular a interação entre os estudantes e mobilizar suas estruturas cognitivas.

Após a apresentação do vídeo foi dado sequência a atividade, e então cabia a eles a levantarem hipóteses referentes às imagens contidas no roteiro. $O$ diálogo entre eles nesse momento foi intenso, pois cada um tentava explicar de uma forma o que aconteceria com a roda de bicicleta. Frequentemente eles me chamavam para confirmar o que aconteceria ou tirar dúvidas sobre como o rapaz da figura segurava a roda, como ele à girava e sobre o sentido de rotação dela.

É possível observar que a estrutura do roteiro favoreceu o diálogo dentro da sala de aula e estimulou a busca por respostas. Tais características estão presentes nas concepções construtivistas de ensino, as quais defendem um ambiente com estudantes ativos.

As atividades experimentais como um todo, constituem parte fundamental desta proposta didática e os registrados no diário de bordo demonstraram que além de serem apresentadas após a abordagem do conteúdo, elas são efetivas se incluídas na própria abordagem. Portanto, isso não significa que o planejamento não foi adequado, mas sim, que é flexível e pode ser adaptado de acordo com a característica de cada professor ou turma.

\section{Questionários}

Para análise dos questionários pré e pós-teste foram criadas categorias de acordo com os conteúdos que os integram. Assim sendo, as categorias foram denominadas da maneira a seguir: velocidade angular, torque, momento angular e conservação do momento angular. Os testes foram analisados de forma a identificar se houve evolução conceitual dos estudantes após a aplicação da proposta. A análise está limita às respostas de 12 estudantes (E1, E2,... e E12) pois três deles deixaram de responder o questionário pós-teste. 


\section{Velocidade Angular}

A primeira questão dos testes (Q1: O cavalo de madeira na parte mais externa de um carrossel move-se mais rapidamente do que um cavalo que está mais para o interior do carrossel? Ou ambos têm a mesma rapidez?) é direcionada a encontrar evidências que demonstrem se os estudantes conhecem e entendem, os conceitos de velocidade linear e velocidade angular, e se compreendem a relação que há entre elas num movimento rotacional.

Ao responder corretamente uma questão sobre a rapidez de um corpo que descreve um movimento rotacional, é preciso estar ciente que há vários tipos de grandezas envolvidas, dentre estas estão a velocidade linear e velocidade angular. A resposta consistente para esse tipo de pergunta deverá então ser elaborada mencionando uma ou as duas grandezas, como por exemplo, "o cavalo localizado na parte mais externa terá velocidade angular igual aos demais, enquanto a velocidade linear será maior para o cavalo que estiver mais afastado do centro de rotação do carrossel".

Ao analisar as respostas do pré-teste, pode-se observar que unicamente o estudante E1 (Sim, a velocidade linear dele será maior mais alta, porém a angular é a mesma, estando os dois ligados ao mesmo eixo) demonstrar ter conhecimentos corretos relacionados aos conceitos envolvidos no movimento rotacional.

Alguns estudantes deram respostas com características semelhantes o que permite agrupa-los da seguinte forma: E5, E9 e E10 (ambos têm a mesma rapidez); E6, E11 e E12 (ambos têm a mesma velocidade); E3 e E8 (O externo é mais rápido); E4 (Ambos têm a mesma rapidez, pois o carrossel todo anda na mesma velocidade); E7 (Se ambos estiverem com a mesma frequência, o de fora se moverá mais rápido), enquanto que o estudante E2, diz não ter certeza de como responder.

Os resultados indicam que a maioria dos estudantes (dez) possuem concepções previas das grandezas necessárias para caracterizar um movimento rotacional, mas existem lacunas que não permitem uma identificação, diferenciação ou compreensão correta dos conceitos de velocidades linear e angular.

Ao serem analisadas as respostas dadas para a Q1 no pós-teste, nota-se que houve uma evolução na compreensão dos estudantes após a aplicação da proposta didática. A maioria deles (10) passam a utilizar o conceito de velocidade angular em suas respostas e mostram que conseguem diferencia-la da velocidade linear. Isto pode ser observado, por exemplo, nas respostas dos estudantes E6 (Mais rapidamente em velocidade linear, igual em velocidade angular), E10 (A velocidade linear muda e a velocidade angular é a mesma), E8 (A velocidade angular é a mesma mas a velocidade linear diferente), e E11 (Depende, se estivermos falando de velocidade angular é a mesma, mas a linear de fora é maior que a de dentro).

\section{Torque}

A segunda questão (Q2: como denominamos a grandeza responsável por colocar corpos em movimento de rotação) dos testes apresenta um problema que pretende identificar se os estudantes compreendem a diferença entre força e torque. 
É notável, no senso-comum, que as pessoas confundam os conceitos de torque e de força. De fato, há uma relação entre essas grandezas. O torque, também chamado de momento de força, é relativo ao movimento de rotação de um corpo. A grandeza fornece uma medida de como a ação de uma força pode causar o modificar o estado de movimento de rotação de um corpo. A magnitude do torque depende do valor da força e de onde ela está sendo aplicada no corpo. $\mathrm{O}$ torque é sempre definido em relação a um ponto específico. Se a linha de ação da força passa por cima desse ponto o torque é nulo e consequentemente, o corpo apresentará tendência a movimento linear e não rotacional. Caso a força seja aplicada numa outra linha de ação, diferente da anterior, existira um braço de alavanca e aparecerá um esforço de torsão, um torque, e o corpo poderá entrar em movimento de rotação. Por esse motivo a grandeza responsável por colocar corpos em rotação é o torque.

Analisando os dados do pré-teste identifica-se que apenas o estudante E3 (Momento de uma força) respondeu corretamente à questão, utilizando adequadamente o conceito de torque, e em relação à diferença de termos utilizados no pré-teste e no pós-teste, indica que o estudante ampliou seu vocabulário, passando a identificar o termo momento de força como equivalente ao torque.

Os estudantes: E2, E4, E5 e E6, disseram não saber responder. E1, E7 e E9 indicaram que a grandeza responsável por iniciar o movimento de rotação é a aceleração centrípeta, enquanto que, E8, E10 e E11 falam que é uma força. A aceleração centrípeta, embora seja fundamental no movimento circular, ela surge devido a Força centrípeta que "puxa" o corpo em rotação para o centro da trajetória circular. Evidencia-se das respostas dos alunos (tanto para a Q1, como para a Q2) que os conhecimentos prévios dos estudantes não os permitem elaborar respostas corretas e completas fazendo uso deles.

Com base nos dados obtidos, após aplicação do produto, é possível identificar evolução conceitual por parte de todos os estudantes, pois passaram a mencionar corretamente a grandeza torque em suas respostas. Nesse caso, podemos concluir que o planejamento das atividades na proposta didática foi eficaz, no sentido de ampliar vocabulário e de comparar conceitos que anteriormente possuíam, mas que não se sustentavam como resposta ao problema.

\section{Momento Angular}

A questão três (Q3: Existem helicópteros dotados de duas hélices principais. Descreva como devem ser o sentido de rotação das hélices para dar estabilidade ao helicóptero. Justifique a resposta) foi ilustrada utilizando uma foto de um helicóptero que possui duas hélices. Q3 visa identificar se os estudantes conhecem o conceito de momento angular, assim como o princípio de conservação do momento angular.

No pré-teste, a maioria dos estudantes forneceram respostas erradas para esta questão: E7 (não sei), E5 e E9 (em branco), E3 (... se movem simultaneamente), E1 (Tem duas opções. Uma da certo e a outra não: Ambas ao mesmo sentido ou cada uma para um lado), E6 e E11 (Mesmo sentido) e E10 (Mesmo eixo). Os estudantes E2, E4, E8 e E12 responderam que "as hélices deveriam se mover em sentidos diferentes". Esta resposta é correta, mas os estudantes não justificaram a necessidade de que as hélices se movimentem em sentidos opostos. Em outras 
palavras, a resposta não dá nenhuma evidencia de que os estudantes conheçam e compreendam as grandezas físicas envolvidas no fenômeno físico por trás do movimento rotacional das hélices do helicóptero.

Para responder corretamente a esta questão é necessário conhecer e entender o conceito de momento angular e suas propriedades estabelecidas pelo princípio de conservação do momento angular. Antes de iniciar o movimento, as hélices, e o helicóptero como um todo, têm momento angular nulo. Quando as hélices começarem a girar, adquirem momento angular que é transmitido ao helicóptero. De acordo com o princípio de sua conservação, é necessário que o helicóptero continue com momento angular nulo. Para que isso ocorra as hélices devem giram em sentidos opostos, adquirindo assim momentos angulares opostos, que ao serem transmitidos para o helicóptero se anulam e ele consegue manter a sua estabilidade.

Analisando os dados do pós-teste para os estudantes E2, E4, E8 e E12, que já tinham respondido de forma correta a Q3, verifica-se que eles acrescentam o termo momento angular as suas respostas (Uma hélice no sentido horário, e outra no sentido anti-horário de maneira que os seus momentos angulares são opostos; Devem girar em sentidos opostos por causa do momento angular) isso mostra uma evolução conceitual por parte destes estudantes após a aplicação da proposta.

Os estudantes que no pré-teste, não se sentiram aptos a responder à pergunta (E5, E7 e E9), ou deram respostas inconsistentes (E1, E3, E6, E10 e E11), mostram evolução após aplicação da proposta pois nas suas respostas à mesma questão do pós-teste passam a indicar que os movimentos das hélices do helicóptero devem ser em sentidos opostos. Novamente, mencionar apenas o sentido de rotação, não pode ser considerado incorreto, no entanto, a resposta não é justificada.

Embora a utilização do termo momento angular não esteja presente nas respostas, não seria adequado dizer que a proposta não tenha contribuído no desenvolvimento dos estudantes, pois há, de uma forma ou outra, evolução. Vale ressaltar também, que é preciso trabalhar com discernimento as grandezas vetoriais, para que os estudantes consigam compreender que um vetor pode ser associando a diferentes tipos de grandezas.

\section{Conservação do Momento Angular}

A quarta questão (Q4: Descreva com suas palavras o que acontece se for empurrado o anel externo, de um giroscópio quando o rotor estiver girando em sentindo anti-horário, ver Figura 1) dos testes objetiva identificar se os estudantes compreendem o fenômeno físico por trás do funcionamento do giroscópio.

Quando o giroscópio está em alta rotação, o mesmo tende a manter o seu eixo de rotação apontado na mesma direção, pois há momento angular e ele se conserva na ausência de torque aplicado. No entanto, ao ser aplicada uma força em algum dos seus anéis, o anel tende a permanecer parado, enquanto que o outro começa a girar. Na Figura 1, foram representadas a direção da força, o vetor que descreve o ponto de aplicação da força, o momento angular e do sentido de rotação do rotor. Nessas condições, a direção momento angular é na direção do torque, ou seja, o eixo do rotor irá girar em torno do eixo y, em sentido anti-horário. 
Analisando os dados do pré-teste, é possível identificar que muitos optaram por não responder à questão, ou disseram não se sentir aptos a respondê-la (E1, E4, E5, E6, E7, E8, E9 e E10). Os estudantes E2, E3, E11 e E12, deram respostas inconsistentes com a situação: Creio que cada um dos eixos irá girar em um diferente sentido e a roda interna irá girar; Vai aumentar a velocidade; Vai virar o ângulo de rotação; O eixo irá oscilar sobre o eixo y. Contudo, é aparente que estes estudantes conhecem ou já tenham visto situação semelhante, mas é evidente que não sabem explicar o fenômeno por trás do seu funcionamento.

Após a aplicação da proposta didática, os dados do pós-teste, indicam progresso por parte da maioria dos estudantes, como é o caso do E1, E2, E3. E4, E6, E7, E8, E10, E11 e E12. Os estudantes E1 e E2 descrevem respostas parecidas (E1 - O eixo irá oscilar sobre o eixo y; E2 - Ele irá girar no sentido oposto ao que foi empurrado, e a parte menor irá girar no eixo y), a suposição dos educandos para o problema, é de que o eixo rotor entre em rotação no eixo y; de fato isso ocorre, uma vez que a direção do torque é paralela ao eixo z e tem sentido para cima. Os outros estudantes E3, E4, E6, E7, E8, E10. E11 e E12 passam a identificar que o movimento do rotor será na direção do torque, o que é também condizente com o que ocorre no funcionamento do dispositivo, caso sofra ação de torques externos. Para ilustrar, a seguir algumas das respostas destes estudantes: Ele irá girar no sentido oposto ao que foi empurrado; $O$ eixo do rotor irá se mover na direção do torque; O rotor interno gira na direção do torque; Vai girar na direção do torque; Vai girar o do meio em direção paralela ao torque.

\section{Considerações finais}

O estudo de tópicos da mecânica rotacional permite uma visão mais abrangente do mundo que vivemos. Conceitos como velocidade angular, momento de inércia, torque e momento angular e sua conservação são relevantes para a compreensão de fenômenos que envolvem movimentos rotacionais. Neste estudo, constatamos que esses componentes curriculares, mesmo que reconhecidos como importantes por pesquisadores (RUBINI; KURTENBACH; SILVA, 2015) e pela legislação para a formação dos jovens, enfrentam obstáculos quanto a sua inserção no EM.

Parecem existir dois fatores relevantes associados à ausência da temática em sala de aula na educação básica: a dificuldade que os professores apresentam em relação à compreensão do conteúdo (SILVA, 2012); e a falta de conteúdo nos livros didáticos (COSTA, 2015). Por outro lado, tem-se a falta de materiais didáticos acessível ao professor. Tendo em conta estas evidências, optamos em contribuir com a elaboração de material didático destinado aos professores de Física do EM para que se sintam subsidiados ao trabalhar tópicos da mecânica rotacional. Assim sendo, e fundamentados em pressupostos construtivistas foi organizada uma proposta didática que privilegia o uso de um conjunto de atividades didáticas: problematizações, animações em GIF, hipertextos, vídeos e atividades experimentais. A proposta foi dividida em encontros e a metodologia de ensino parte de que para iniciar um conteúdo novo seja utilizada a problematização. Sugere também, contextualizar os conceitos e utilizar diferentes atividades auxiliadas por recursos digitais e as atividades experimentais. 
A proposta foi avaliada por meio da sua aplicação numa turma de professores de Física em formação inicial. A análise das anotações feitas no diário de bordo, permitiu fazer algumas reflexões sobre o uso de problematizações iniciais, recursos digitais e as atividades experimentais.

Quanto às problematizações iniciais, verificamos que elas ajudaram o professor na identificação de conhecimentos prévios dos estudantes, na condução dos alunos para a tomada de consciência e na incitação pela busca de respostas por parte dos estudantes. O uso combinado de recursos digitais e atividades experimentais possibilitaram: o contato com novos dispositivos; a aproximação de situações pouco cotidianas; a representação visual de grandezas abstratas; e, a motivação dos estudantes. É importante destacar que as problematizações, os recursos digitais e as atividades experimentais foram fundamentais para criar um ambiente de diálogo e interação entre os sujeitos do processo, assim como a de contextualização dos conceitos estudados.

Quanto aos questionários pré e pós-teste, os resultados indicam que as atividades da proposta didática, juntamente com os recursos utilizados, colaboraram para uma evolução conceitual dos estudantes, assim como permitiram que eles ampliarem suas visões na análise dos movimentos rotacionais, e a identificação de novos símbolos e novas grandezas que são fundamentais nos movimentos rotacionais.

Por fim, acreditamos que estratégias como as sugeridas nesta proposta didática podem auxiliar o professor, no processo de ensino, a: motivar os estudantes para a aquisição de um novo conhecimento, identificar os conhecimentos prévios dos estudantes, promover a interação aluno-aluno e aluno-professor, promover o envolvimento dos estudantes no processo de ensino. Os dados também indicam que o planejamento didático pedagógico possibilitou criar um ambiente em que os estudantes são agentes ativos nas atividades desenvolvidas, assim como nas discussões e reflexões, e o professor assume a postura de mediador e/ou facilitador do processo de ensino e aprendizagem.

\section{Referências bibliográficos}

AZEVEDO, Dácio A. Dinâmica de Rotação para o Ensino Médio com o uso de experimentos de baixo custo. 2015. Dissertação (Mestrado em Ensino de Física) - Universidade Federal Rural do Semi-Árido, Mossoró, 2015.

BARBOSA, Wilton G. Inserção de conceitos de Dinâmica Rotacional no Ensino Médio através do laboratório mão estruturado mediado por videoanálise. 2016. Dissertação (Mestrado em Ensino de Ciências) - Universidade Tecnológica Federal do Paraná, Curitiba,2016.

BARDIN, Laurence. Análise de conteúdo. Tradução de Luís Antero Reto e Augusto Pinheiro. 3. ed. Lisboa: Edições 70, 2004.

BORGES, Tarcisio. Novos rumos para o laboratório escolar de ciências. Caderno Brasileiro de Ensino de Física, v. 19, n. 3, p. 291-313, dez. 2002. 
BRASIL. Base Nacional Comum Curricular. Brasília: Ministério da Educação, 2018.

- PCN+ Ensino Médio: orientações educacionais complementares aos Parâmetros Curriculares Nacionais. Brasília: Ministério da Educação, 2002.

COPPETE, Maria C. Diários de bordo e ensaios pedagógicos: possibilidades para pensar a formação de professores na modalidade de educação a distância. In: SEMINÁRIO INTERNACIONAL HISTÓRIA DO TEMPO PRESENTE, 2, 2014, Florianópolis. Anais. Florianópolis, UFSC, 2014.

COSTA, Jefferson M. Proposta de uma Metodologia para abordagem da Conservação do Momento Angular no Ensino Médio. 2015. Dissertação (Mestrado em Ensino de Física) Universidade de Brasília, Brasília, DF, 2015.

DE JESUS, V. L. B. et al. Understanding the gyroscope sensor: a quick guide to teaching rotation movements using a smartphone. Physics Education, v. 54, n. 1, p. 015003, 2018.

DELIZOICOV, Demétrio. Problemas e Problematizações. In: PIETRECOLA, M. (Org.). Ensino de Física: conteúdo, metodologia e epistemologia numa concepção integradora. Florianópolis: UFSC, 2001.

GIL, Antonio C. Métodos e técnicas de pesquisa em ciência social. 6. ed. São Paulo: Atlas, 2008.

LABURÚ, Carlos E.; CARVALHO, Marcelo. Controvérsias construtivistas e pluralismo metodológico no ensino de ciências naturais. Revista Brasileira de Pesquisa em Ensino de Ciências, Bauru, v. 1, n. 1, p. 57-68, jan./abr. 2001.

MORAN, José M. Influência dos meios de comunicação no conhecimento. Ciência da Informação, Brasília, v. 23, p. 233-238, maio/ago. 1994.

PINHO-ALVES, Jose. Atividades experimentais: do método à prática construtivista. 2000. Tese (Doutorado em Educação) - Universidade Federal de Santa Catarina, Florianópolis, 2000.

RIBEIRO, Luis Roberto de Camargo. Aprendizagem baseada em problemas (PBL): uma experiência no ensino superior. São Carlos: EdUFSCar, 2010.

SILVA, Laurielza C. B. O Discurso dos Professores de Maringá e região sobre a abordagem do Momento Angular e do Torque no Ensino Médio. 2012. Dissertação (Mestrado em Ensino de Ciências e Matemática) - Universidade Estadual de Maringá, Maringá, 2012.

TRIVIÑOS, Augusto N. S. Introdução à pesquisa em ciências sociais: a pesquisa qualitativa em educação. 4. ed. São Paulo: Atlas, 1994.

ROSA, C.T.W. da, ROSA, A.B. Ensino de Física: objetivos e imposições no ensino médio. Revista Electrónica de Enseñanza de las Ciencias Vol. 4 № 1 (2005)

ZABALZA, Miguel A. Diários de aula: contributo para o estudo dos dilemas práticos dos professores. Porto: Porto Editora, 1994. 